and tissues below the anorectal line. In other words, the injections are made only in a practically painless area.

Dr. Terrell gets good results because he knows the rectum, its pathology and its anatomy. He knows what tissues to avoid, and what symptoms to expect. The method is valuable in the hands of a man who takes the trouble to find out how to use it, and how to avoid complications. In the hands of an untrained practitioner, it is decidedly dangerous, and not to be recommended for general use. I have tried the solution Dr. Terrell recommends, but have experienced a little more trouble, probably because I did not stretch the sphincter muscles prior to starting treatment, depending on the anesthetic qualities of quinin and urea hydrochlorid to lessen the tendency to sphincter spasm. This year I reported a case of anaphylaxis occurring from the use of quinin and urea hydrochlorid. This does not condemn the solution, but should make us careful in our selection of patients.

Dr. A. E. ChACE, New York: I do not think I ought to let this paper go by without a word of caution from a very young man, and a plea for real surgery in hemorrhoids. I have seen several hundred of these operations and, fortunately, only two deaths that could be attributed directly to the operation. The first was performed by means of a so-called sterile water anesthesia in the clinic. That man got a gas bacillus infection along the perineum, scrotum, thighs, and the anterior abdominal wall sloughed off before he died. The second operation was performed after the injection of quinin and urea. The prostatic plexus seemed to bc first involved in the infection; there were abscesses in the liver, and death was of course caused by pyemia. Those are only two cases, it is true, but, just a word of caution: This is not a procedure that is without danger, and few procedures around the rectum, where it cannot be disinfected, are free from danger unless we have perfect drainage.

DR. D. C. MacKenNy, Buffalo: I agree thoroughly with Dr. Terrell. I have used this method a great many times in cases of tuberculous and old people, in whom one would not want to operate, and the results were all that he claimed for the treatment.

Dr. George B. Evans, Dayton, Ohio: I listened to Dr. Terrell's paper last year with not a great deal of favor and would deem myself an ingrate today if I did not rise and make an apology to him in public. On May 28 and $29 \mathrm{I}$ had the pleasure of being the guest of Dr. Terrell and witnessed his work on ten or twelve patients. Unfortunately for $\mathrm{mc}$, none of those patients received the first injection. They were all patients who had received one, two, three, four or five injections. I also had the opportunity of being out in his waiting room. He did not know who was out there and the patients did not know I was a physician, and I listened to those patients tell what a good fellow Dr. Terrell is. They thought I was a patient. I asked them if there was any pain, and if one was laid up after the treatment, and I got a negative answer in every instance. I was there free hand and I watched this work carefully, and I want to say that I am convinced that he is doing good work and that these patients are cured. I have not only seen him inject these patients, but with his permission have examined a number of them.

Dr. Emmett H. Terrell, Richmond, Va.: The case reported by Dr. Chase in which infection and death followed the injection of hemorrhoids is unfortunate. I think a man doing this work should be careful of his technic. The hemorrhoids must be cleaned off with an antiseptic solution and the work done with as much care as if he were doing a surgical operation. If the work is done properly there will be few complications. Of course, we are working in an area difficult to clean, and there is always a possibility of infection.

Preventive Medicine in Turkey.-The whole problem of preventive medicine in Turkey is practically untouched. It involves the changing of a whole country from a backward, unprogressive one, where filth and disease make it a real menace to the world, into a clean, liveable country, one which might become progressively a real resource to the world's civilization.-A. R. Hoover, M.D., The Survey.

\section{AUTOINTOXICATION IN CHRONIC CONSTIPATION *}

\author{
HORACE W. SOPER, M.D. \\ ST. LOUIS
}

The group of symptoms generally recognized as attributable to intestinal toxemia is too well known to require recapitulation. A priori, the most striking fact that presents itself is the great similarity between the symptoms referable to focal infection and those of intestinal toxemia. This analogy at once suggests that the toxemia associated with chronic constipation may have a bacterial origin. In other words, that an infectious agent is present in the intestine itself. This view is supported by the recent work of Lynch and McFarland, ${ }^{1}$ Satterlee, ${ }^{2}$ Sailer, ${ }^{3}$ Smithies, ${ }^{4}$ Turck, ${ }^{5}$ Barclay, ${ }^{6}$ and others. As a contribution to this phase of the subject $I^{7}$ have recently reported a series of cases of pus infection of the rectum and lower colon as revealed by proctosigmoidoscopy.

Clinicians have long maintained that constipation per se could not be considered a disease entity, and have pointed out that persons in good health may defecate once or twice a week without resulting subjective or objective symptoms. However, the vast majority of individuals do develop symptoms when the bowel function is inadequate. In the symposium on intestinal stasis at the recent meeting of the American Gastro-Enterological Association, Einhorn, Smithies, Lynch, Draper and others emphasized the view that a diseased intestine is really necessary for the production of symptoms incident to chronic constipation. It appears that the question of absorption of toxic material depends on the integrity of the intestinal wall.

When confronted by a case that presents symptoms that we have learned to attribute to autointoxication, our first duty is to search for foci of infection. Investigation must be made of the teeth, tonsils, nasal sintuses, genito-urinary system, and of the intestine itself, not neglecting the rectum and lower colon. When the search is conducted thoroughly, we shall find that our cases of idiopathic autointoxication will diminish in much the same manner that the term neurasthenia is now applied to a constantly decreasing number of patients. In some cases, however, the most careful search will fail to reveal a focus of infection. Even here we may presume that changes have occurred in the mucosa that at present are not determinable by our diagnostic methods. 'Turck's suggestion that venous stasis in the wall of the intestine may produce an increased permeability to the passage of bacteria is plausible.

* Read before the Section on Gastro-Enterolngy and Proctology at the Sixty-Eighth Annual Session of the American Medical Association, New York, Junc, 1917

1. Lynch, J. M., and McFarland, W.: Colonic Infections: Some Rarely Observed Lriclassified Types, The Journal A. M. A., Sept. 23, 1916 , p. 943 .

2. Satterlee, G. R.: Chronic Intestinal Stasis, Am. Jour, Med. Sc. 1916, 152, 727; TuE Journat A. M. A., Dec.9, 1916, p. 1729.

3. Sailer, Joseph: Three Cases of Colon Infection, read at the mecting of the American Gastro-Enterological Association, May, 1917. To be published.

4. Smithies, Frank: Chronic Intestinal Stasis and Its Associated 4. Smithies, lrank: Chronic Intestinal Stasis and Its
So-Called Toxemia, Surg., Gynec. ard Obst., 1916, $\mathbf{2 2 ,} 57$.

5. Turck, F. B.: Diseases Produced by the Bacillus Coli Communis in the Intestine: Etiology, Diagnosis and Treatment, Internat. Clin., 11,30 .

6. Barclay, Harold, and McWilliams, C. A.: Intestinal Stasis, Am. Jour. Med. Sc., June, 1916, p. 822 .

7. Soper, H. W.: The Mucosa of the Rectum and Sigmoid as : Focus of Infection, Boston Med. and Surg. Jour., May 31, 1917.

8. Turck, F. B.: Intestinal Venous Stasis: Diffusion of Bacteria and Other Colloids, Boston Med. and Surg. Jour., 176, 663. 
We must admit that toxemia may result from chemical changes in the intestinal contents. In this connection the phenomena of anaphylaxis as exhibited by food sensitization must be borne in mind. ${ }^{\circ}$

Abnormal metabolism of the food protein is a factor to be considered in the production of intestinal toxemia. This aspect of the question is well stated by Brown, ${ }^{10}$ who says :

Back of the mechanics of digestion lies a problem far more complicated, far more difficult to solve, the problem of congenital or acquired hypersensibility to certain stimuli; the question of the overproduction of certain toxic substances, their chemical nature and their possible specificity, and various other questions involving more definitely physical factors, notably absorption and osmosis.

Brown's cases showed marked improvement on a low protein diet. In my own work I have often noted the good effects produced in certain cases of toxic headaches by sharply limiting the protein and reducing or omitting sugar from the dietary. Patients of this class usually present excessive indicanuria, much colonic flatus, and frothy fermentative feces. Moreover, they are, as a rule, in the habit of consuming large quantities of cane sugar. Possibly the presence of an excess of sugar may be a factor in determining the defective digestion or utilization of the food protein in susceptible individuals. Apropos of the carbohydrate element, the work of Pemberton ${ }^{11}$ is especially interesting. He produced good results in cases of theumatoid arthritis by a radical reduction of the carbohydrate in the dietary.

Besides bacterial infection, disturbances in the mechanics of digestion, and aberrant biochemical processes, we must consider a fourth important factor in the development of toxic conditions, namely, the central nervous system. Disturbances of metabolism are frequently encountered in the observation of the functional psychoses, particularly the manic depressive type. One such case deserves special mention. A patient whom I have observed in conjunction with Dr. Frank R. Fry, for the past three years, developed during the depressive phase, glycosuria, acetonuria, and indicanuria. In the intervals between the attacks, the urine is entirely free from these substances. Numerous cases could be cited in support of the contention that toxic states may arise primarily as a result of disturbances in the central nervous system, that they are frequently evanescent in character, and that they disappear regardless of the form of treatment instituted. I emphasize the nervous element in these cases particularly as a warning against giving credence to reports of cures, especially operative results, in patients of the manic depressive type. Milder forms of psychic and somatic disturbances are also elements of importance in the consideration of the etiology, symptomatology and treatment of intestinal toxemia.

The indiscriminate use of cultures of the Bacillus bulgaricus, now so much in vogue as a remedy for autointoxication, is open to serious objections. Even in carefully selected cases its value as an adjunct to treatment is questionable. The prevailing impression in regard to its therapeutic worth is probably due to the great food value of fermented milk. Another reason for its popularity is that it offers a remedy that

9. Longcope, W. F.: Susceptibility of Man to Foreign Proteins, Am. Jour. Med. Sc., 1916, 152, 625. 10. Brown, $T$, R.: Clinical Investigations on Intestinal Auto-Intoxi cation, Especially as Regards the

11. Jemberton, Sc., 1916, 152, 845. and Treatment of Rheumatoid Arthritis, Am. Jour. Med. Sc., 1916, 151, 351. the busy doctor may use without subjecting his patient to the ordeal of a carefully adjusted regimen.

The researches of Herter and Kendall, ${ }^{12}$ Raehe, ${ }^{13}$ Rettger, ${ }^{14}$ Horton, ${ }^{15}$ Hull ${ }^{16}$; Einhorn, Wood and Zublin, ${ }^{17}$ and Rosenberg, ${ }^{18}$ and others have shown the fallacy of attempts to secure the implantation of the Bacillus bulgaricus in the intestinal tract. Furthermore, they have demonstrated that diet is the most important factor in determining the character of the bacterial flora.

From the standpoint of economics, the loss in this country must be enormous, when we consider the large expense incurred in the production and distribution of cultures of the Bacillus bulgaricus. ${ }^{19}$

The daily use of purgatives is contraindicated, since they disturb the normal peristaltic rhythm. Moreover, the practice of flushing the colon by drugs or the use of water enemas is objectionable, because such procedures result in the reduction of the contents of the colon to a liquid or semiliquid state, a condition that probably facilitates the absorption of toxic material. I have made frequent sigmoidoscopic examination of such cases and have found that the mucosa is constantly coated by a layer of thin fecal matter. The same condition is present in many cases of chronic diarrhea-cases which exhibit marked symptoms of intestinal toxemia. In these cases we have a real "stasis," different from the usual conception of an accumulation of a large mass of fecal matter, but a retention probably much more injurious to the mucous membrane of the bowel.

\section{CONCLUSIONS}

1. Treatment should be directed against any existing infectious agent.

2. Reliance should not be placed on the Bacillus bul. garicus as a corrective agent.

3 . The regular use of cathartics and water enemas must be avoided.

4. An initial radical change should be made in the dietary in an attempt to alter the bacterial flora.

5 . The problem of the restoration of colonic function may demand the employment of all our therapeutic resources, medicinal, dietetic, hygienic and surgical. Wall Building.

12. Herter, C. A., and Kendall, A. I.: An Observation on the Fate of the Bacillus Bulgaricus (in Bacillac) in the Digestive Tract of a Monkey, Jour. Biol. Chem., 1908, 5, 293

13. Raehe, A. H.: A Study of the So-Called Implantation of the Bacillus Bulgaricus, Jour. Infect. Dis., $1915, \mathbf{1 6}, 210$.

14. Rettger, L. F.: The Influence of Milk Feeding on Mortality and Growth and on the Character of the Intestinal Flora, Jour. Exper. Med., $1915, \mathbf{2 1}, 365$.

15. Rettger, L. F., and Horton, G. D.: A Comparative Study of the Intestinal Flora of White Rats Kept on Experimental and Ordinary Mixed Diets, Centralbl. f. Bakteriol., Orig., 73,362

16. Hull, T. G., and Rettger, L. F.: The Influence of Milk and Carbohydrate Feeding on the Character of the Intestinal Flora, Jour. Bacteriol., 1917, 2, 47.

17. Einhorn, Max; Wood, Francis, and Zublin, Ernst: Ueber den Einfluss der Milchsaure-Bazillen auf die Darmflora, Arch. f. Verdau ungskr., 16, Part, 3, p. 300 .

18. Rosenberg, Ernst: Kritik des Yoghurt und die Indikationen fü seine Anwendung, Arch. f. Verdauungskr., 15, Part 4, p. 458.

19. Manufacturers of the tablets and liquid cultures do not state in their literature that the fermentation of milk can be carried on simply by reserving a small portion of the fermented milk as a "yeast" to be added to the milk instead of using a tablet each time. I know of many housewives who successfully ferment the milk in this manne and who rarely resort to the tablet or liquid culture.

Husband and Wife-Remedy of Wife for Sale of Opium to Her Husband.-Where the disabilities of coverture are removed and the statute gives every person a right to damages for detriment suffered from the unlawful act of another, a woman, it is held in the South Dakota case of Moberg v. Scott, L.R.A.1917D, 732, may, under the statute and a common law, recover damages for loss of consortium and support through the unlawful sale of opium to her husband. 